Article

\title{
Simple Electrochemical Synthesis of Polyethylenimine- Encapsulated Ag Nanoparticles from Solid AgCl Applied in Catalytic Reduction of $\mathrm{H}_{2} \mathrm{O}_{2}$
}

\author{
Kyung Tae Kim ${ }^{1}$ and Deog-Su Park ${ }^{2, *}$ \\ 1 Department of Molecular Science Technology, Institute of BioPhysio Sensor Technology (IBST), \\ Pusan National University, Busan 46241, Korea; kyungtae81@hanmail.net \\ 2 Institute of BioPhysio Sensor Technology (IBST), Pusan National University, Busan 46241, Korea \\ * Correspondence: dsupark@pusan.ac.kr
}

Received: 4 November 2020; Accepted: 2 December 2020; Published: 4 December 2020

\begin{abstract}
We report a simple and environmentally friendly synthesis of polyethylenimine (PEI)-encapsulated Ag nanoparticles (AgNPs) by a direct electroreduction of solid AgCl. The AgNPs, characterized by field-emission scanning electron microscopy (FE-SEM), X-ray photoelectron spectroscopy (XPS), and energy dispersive X-ray spectroscopy (EDS), revealed that AgNPs diameters (100-500 nm) depended on the loading of the $\mathrm{AgCl}$ precursor. Using cyclic voltammetry (CV), it was confirmed that the AgNPs had a catalytic effect on the electrochemical reduction of $\mathrm{H}_{2} \mathrm{O}_{2}$. The obtained AgNPs were subsequently used to construct an electrochemical $\mathrm{H}_{2} \mathrm{O}_{2}$ sensor exhibiting a low detection limit $(1.66 \mu \mathrm{M})$ and a wide linear response range, with real-life tests indicating an insensitivity to common interferents and confirming the potential use of the developed technique in diverse applications.
\end{abstract}

Keywords: silver nanoparticles; catalyst; hydrogen peroxide; electrochemical reduction; silver chloride

\section{Introduction}

Silver nanoparticles (AgNPs) have been intensively studied due to their physical and chemical characteristics and are now widely applied in the field of catalysis, biomedicine, and toxicity [1-3]. The AgNPs are manufactured by physical methods [4,5], chemical reduction [6,7], electrochemical reduction [8,9], microwave processing [10], thermal decomposition [11], and biosynthesis [12]. Among these methods, the electrochemical method has advantages in that the process is simple, the purity of silver nanoparticles is high, and size control is easy. Moreover, metal particles can be produced by controlling the voltage or current, and an additional reducing agent is not required. In general, except for a few physical methods $[4,5]$, the silver ion precursors are dissolved in a solution state and reduced to metallic silver. The electrochemical reduction of silver ions to produce AgNPs generally employs potentiostatic [13] or galvanostatic methods [14]. For the optimization of AgNPs' fabrication using electrochemical synthesis, it is necessary to consider parameters such as silver ion precursors and supports of AgNPs. The $\mathrm{Ag}^{+}$ions from water soluble silver salt are required, and $\mathrm{AgNO}_{3}$ is generally used, but pure silver metal is used as a sacrificed anode $[15,16]$. To apply AgNPs for electrochemical applications, supports are needed to fix it on the electrode surface, and several types of supports have been used for this purpose. Depending on the application field and purpose of AgNPs, organic polymers [17], conductive polymers [18-20], and functional nanomaterials [21,22] are frequently used as supports. Electrochemical changes occur at the interface between the solution and the electrode, and silver nanoparticles are formed on the electrode surface through electrochemical reduction processes. However, during the electrochemical reduction of silver 
ions, only some silver ions that are dissolved in the solution are deposited as silver metal on the electrode surface, while most of the silver ions remain in the solution and are discarded. Discarding most of the silver ion precursors dissolved in the solution is economically and environmentally undesirable. To overcome this problem of the electrochemical method, silver ion precursors are not dissolved in solution but fixed to the electrode surface in a solid state and reduced in situ to metallic silver. For this, it would be pertinent to introduce insoluble precursors rather than soluble silver salts. Unlike typical soluble silver salts (e.g., $\mathrm{AgNO}_{3}$ ) commonly used in the preparation of silver nanoparticles [6-22], silver chloride is insoluble $\left(\mathrm{K}_{\mathrm{sp}}=1.8 \times 10^{-10}\right)$ and is therefore suitable as a solid precursor for silver nanoparticles fabrication. In order to reduce solid silver chloride directly on the electrode surface, a membrane is required to fix it on the electrode surface. Polyethylenimine (PEI) is a hydrophilic polymer, containing primary, secondary, and tertiary amino groups, that is negatively charged in neutral aqueous solutions and widely used as a stabilizer in the fabrication of matrix-embedded metal (e.g., Au, Ag, and Pt) NPs [23-25]. One of the important applications of silver nanoparticles is the catalytic effect, which is used to determine $\mathrm{H}_{2} \mathrm{O}_{2}$ by electrochemical methods. The excellent catalytic activity exhibited by the AgNPs allows for an inexpensive and effective $\mathrm{H}_{2} \mathrm{O}_{2}$ detection, and they have therefore been extensively investigated [26-30]. The analysis of $\mathrm{H}_{2} \mathrm{O}_{2}$ based on enzymatic or electrochemical reactions plays an important role in chemistry, biology, clinical control, and environmental protection [30-34].

In the present study, an electrochemical method for fabricating PEI-encapsulated AgNPs by direct electroreduction of solid $\mathrm{AgCl}$ was proposed. The characterizations of AgNPs were investigated by employing scanning electron microscopy (SEM) and X-ray photoelectron spectroscopy (XPS). After fabricating AgNPs on the electrode surface, their electrochemical catalytic effect on the reduction of $\mathrm{H}_{2} \mathrm{O}_{2}$ was evaluated by cyclic voltammetry. The application of AgNPs was examined by measuring the catalytic reduction current according to the concentration of $\mathrm{H}_{2} \mathrm{O}_{2}$ and interfering species. Finally, the reliability of the AgNPs/PEI-decorated electrode was evaluated by determining the $\mathrm{H}_{2} \mathrm{O}_{2}$ concentration in a real sample of human urine.

\section{Results and Discussion}

\subsection{Electrochemical Reduction of $\mathrm{AgCl}$ to $\mathrm{AgNPS}$}

Figure 1 shows the electrochemical behaviors of PEI-coated and PEI-encapsulated $\mathrm{AgCl}$ electrodes. In the PEI-coated electrode, as shown in the inset of Figure 1, no redox current appeared by CV in $0.1 \mathrm{M}$ phosphate buffer solution (PBS, pH 7.0). The AgCl/PEI-decorated electrode was characterized by $\mathrm{CV}$ in $0.1 \mathrm{M}$ PBS at a scan rate of $50 \mathrm{mV} \mathrm{s}^{-1}$.

On the first scan to the negative potential, the reduction of $\mathrm{Ag}^{+}$began at around $-0.1 \mathrm{~V}$ (Figure 1a). During the reverse scan to the positive potential direction, a small current, due to the oxidation of the silver metal initially formed on the electrode surface, occurs around $0.1 \mathrm{~V}[35,36]$. After five repeated scans on the same voltage range, the reduction current decreases, and the oxidation current around $0.5 \mathrm{~V}$ increases significantly (Figure 1b). During the repeated scan, the amount of silver metal deposited on the electrode surface increases, and the oxidation current of the silver metal increases. This is a typical phenomenon that occurs when metal ions are deposited to the electrode surface as metal by a reduction process [37]. Therefore, it was confirmed that the solid-state silver ion precursors fixed on the electrode surface were reduced to silver metal. The potential of $-0.5 \mathrm{~V}$ is sufficient for silver ions of $\mathrm{AgCl}$ to be reduced to silver metal, so in further experiments, a constant voltage of $-0.5 \mathrm{~V}$ was applied for $300 \mathrm{~s}$ to produce silver nanoparticles. The AgNPs are formed by $\mathrm{AgCl}$ immobilized on the electrode surface, not by silver ions in solution, so the process of generating AgNPs is not significantly affected by stirring or sonication of the solution. In addition, when stirring the solution or applying sonication, the polymer membrane of $\mathrm{PEI}$ or $\mathrm{AgCl}$ fixed to the electrode surface may fall from the electrode. Therefore, the electrochemical reduction of $\mathrm{AgCl} / \mathrm{PEI} / \mathrm{GCE}$ was performed in a quiescent solution. 


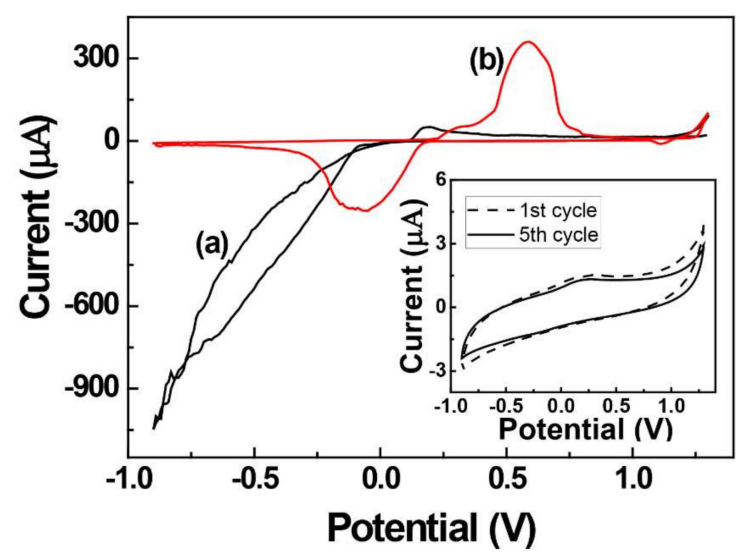

Figure 1. Cyclic voltammograms of the $0.5 \mathrm{wt} / \mathrm{vol} \%$ of $\mathrm{AgCl} / \mathrm{PEI}-$ decorated electrode in $0.1 \mathrm{M}$ PBS ( $\mathrm{pH}$ 7.0) recorded at a scan rate of $50 \mathrm{mV} \mathrm{s}^{-1}$ for (a) the first and (b) the fifth cycle. The inset figure shows the PEI-coated electrode under the same experimental parameter conditions.

\subsection{Characterization of $A g N P s$}

The morphology and nanostructure of AgNPs were evaluated using SEM, XPS, and EDS techniques. Figure 2 shows the FE-SEM images of AgCl/PEI and AgNPs-decorated PEI after electrochemical reduction at different loadings of solid $\mathrm{AgCl}$. In the $\mathrm{AgCl} / \mathrm{PEI}$ electrode before $\mathrm{AgCl}$ is reduced (Figure 2a), uneven small sizes of solid $\mathrm{AgCl}$ particles are shown on the surface of the glassy carbon electrode (GCE). After the electroreduction of $\mathrm{AgCl}$ (Figure 2b-d), the AgNPs are distributed on the surface of the GCE. The SEM images show the successful formation of the AgNPs on the electrode surface. The diameter of the prepared AgNPs increased with increasing AgCl loading due to diffusive aggregation and coalescence, equaling $\sim 100$ and $500 \mathrm{~nm}$ at $\mathrm{AgCl}$ loadings of 0.05 and $0.5 \mathrm{wt} / \mathrm{vol} \%$, respectively.
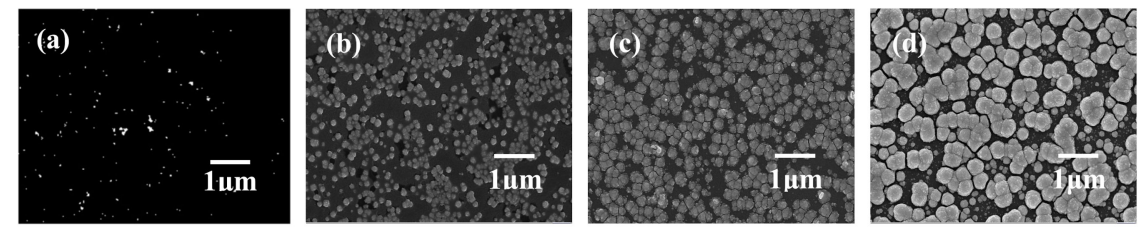

Figure 2. FE-SEM images of (a) AgCl/PEI and Ag nanoparticles-decorated PEI electrodeposited on a glassy carbon electrode under various $\mathrm{AgCl}$ loadings of (b) 0.05 , (c) 0.5 , and (d) $5.0 \mathrm{wt} / \mathrm{vol} \%$, applying a potential of $-0.5 \mathrm{~V}$ and deposition time of $300 \mathrm{~s}$ in a $\mathrm{pH} 7.0$ phosphate buffer solution.

To confirm the formation of AgNPs, the change in the oxidation state of silver before and after the electrochemical reduction was investigated using XPS (Figure 3A). The XPS spectrum of AgCl-decorated PEI revealed the presence of two different species with $\mathrm{Ag} 3 \mathrm{~d}_{5 / 2}$ binding energies of 367.2 and $367.6 \mathrm{eV}$. The former peak was assigned to silver ions $\left(\mathrm{Ag}^{+}\right)$of $\mathrm{AgO}$, whereas the latter was attributed to those in $\mathrm{Ag}_{2} \mathrm{O}\left(\mathrm{Ag}^{2+}\right)$. After the electrochemical reduction, the two peaks of 367.2 and $367.6 \mathrm{eV}$ disappeared, and new peaks appeared at $368.4 \mathrm{eV}$ and $374.4 \mathrm{eV}$. The peaks at $368.4 \mathrm{eV}$ and 374.4 were assigned to $\mathrm{Ag}^{0}$, indicating the presence of metallic AgNPs [38-40] and indicating that they were shifted to positive binding energies when compared to the values observed for bulk Ag (368.1-368.2 eV). This finding reflects the previously reported dependence of the $\mathrm{Ag} 3 \mathrm{~d}$ peak position on the nanoparticle size, with a shift to higher binding energies indicating a decreasing AgNP diameter [41]. From the XPS results, it was confirmed that solid silver chloride was successfully reduced to silver nanoparticles. To verify the composition ratio of $\mathrm{Cl}$ to $\mathrm{Ag}$ atoms during the electrodeposition, an EDS analysis was performed (Figure 3B). The \% atomic content ratios (Cl: Ag) of $\mathrm{AgCl} / \mathrm{PEI} / \mathrm{GCE}$ and $\mathrm{AgNPs} / \mathrm{PEI} / \mathrm{GCE}$ were $29.42 \%$ : $31.58 \%$ and $4.16 \%: 55.84 \%$, respectively. The increasing silver ratio in the AgNPs/PEI/GCE is due 
to AgNPs being fixed on the electrode surface while $\mathrm{Cl}^{-}$is leached out of the electrode surface into the solution.
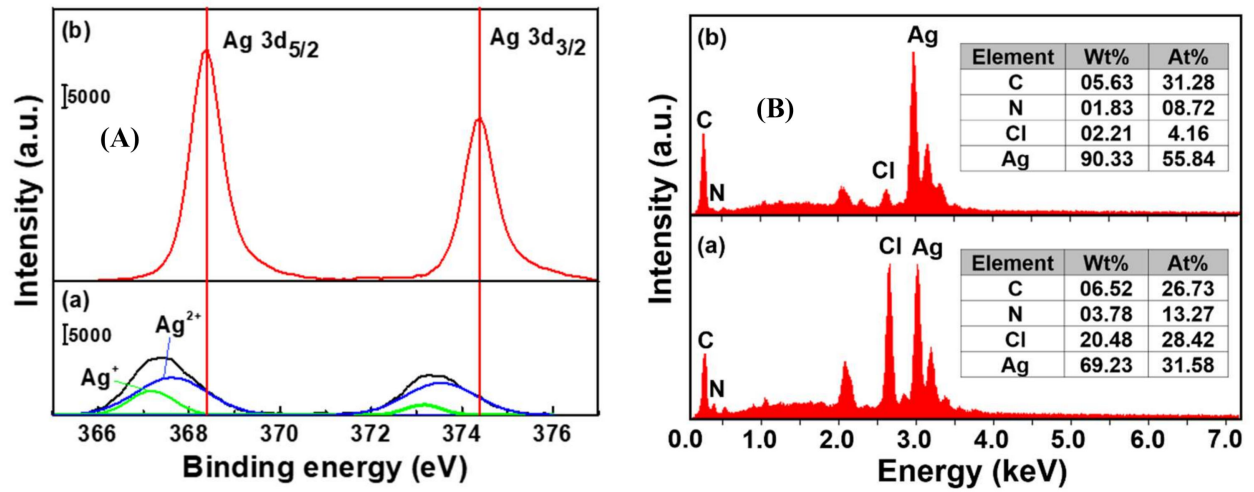

Figure 3. (A) XPS and (B) EDS spectra of the (a) AgCl/PEI/GCE and (b) AgNPs/PEI-decorated GCE.

\subsection{Electrochemical Catalytic Effect of AgNPs for $\mathrm{H}_{2} \mathrm{O}_{2}$ Reduction}

The quantification of $\mathrm{H}_{2} \mathrm{O}_{2}$ is important in various biological and industrial processes [42,43], with electrochemical sensing exhibiting the advantages of a fast detection, low cost, low detection limit, and high specificity. The decomposition of hydrogen peroxide $\left(\mathrm{H}_{2} \mathrm{O}_{2}+2 \mathrm{H}^{+}+2 e^{-} \rightarrow 2 \mathrm{H}_{2} \mathrm{O}\right)$ through the reduction reaction is a well-known process and is catalyzed by AgNPs. The electrocatalytic activity of AgNPs for the $\mathrm{H}_{2} \mathrm{O}_{2}$ reduction was probed by subjecting bare, PEI-coated, and AgNPs/PEI-decorated GCE to a cyclic voltammetry (CV) experiment in the presence of $0.1 \mathrm{mM} \mathrm{H}_{2} \mathrm{O}_{2}$ in $0.1 \mathrm{M}$ PBS at pH 7.0 (Figure 4). At the bare and PEI-coated GCE (Figure 4a,b), small $\mathrm{H}_{2} \mathrm{O}_{2}$ reduction peaks of similar currents were observed around $-0.65 \mathrm{~V}$. This result indicates that the PEI is hydrophilic and does not limit the diffusion of $\mathrm{H}_{2} \mathrm{O}_{2}$ to the electrode surface. On the other hand, the electrocatalytic reduction of $\mathrm{H}_{2} \mathrm{O}_{2}$ in the presence of AgNPs was $-0.32 \mathrm{~V}$, which shifted to the positive direction by about $-0.33 \mathrm{~V}$. The reduction current of $\mathrm{H}_{2} \mathrm{O}_{2}$ at the AgNPs/PEI-decorated GCE was 3.5 times higher than that of the bare GCE (Figure 4c). The change in shift of the electric potential towards the positive direction and the increase in current confirm the electrochemical catalytic effect of AgNPs on the reduction of $\mathrm{H}_{2} \mathrm{O}_{2}$. The reduction current of $\mathrm{H}_{2} \mathrm{O}_{2}$ was investigated according to the content of $\mathrm{AgCl}$. The $5.0 \mathrm{wt} / \mathrm{vol} \%$ of $\mathrm{AgCl}$ did not increase significantly when compared to the $0.5 \mathrm{wt} / \mathrm{vol} \%$, so a $0.5 \mathrm{wt} / \mathrm{vol} \%$ of $\mathrm{AgCl}$ was used for the quantification of $\mathrm{H}_{2} \mathrm{O}_{2}$.

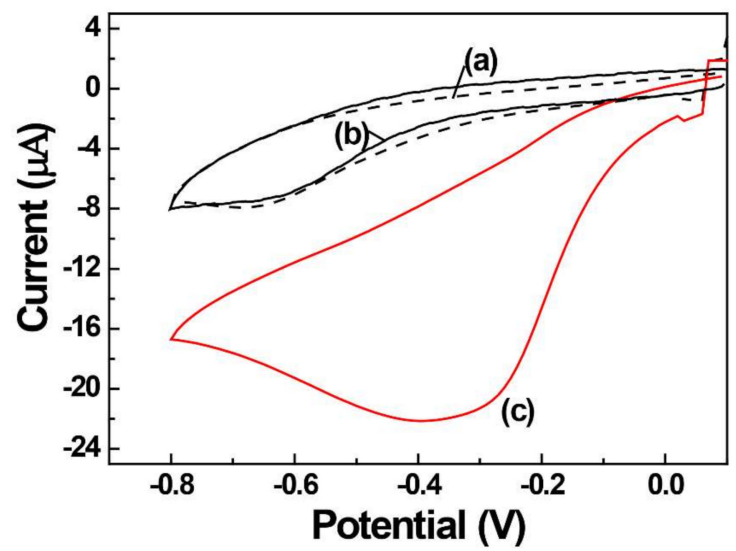

Figure 4. Cyclic voltammograms of (a) bare, (b) PEI-coated, and (c) AgNPs/PEI-decorated GCE.

The sensitivity and calibration curves for the $\mathrm{H}_{2} \mathrm{O}_{2}$ reduction were investigated in the concentration range $0.02-1.0 \mathrm{mM}$ (Figure 5) using cyclic voltammetry in $0.1 \mathrm{M}$ PBS at pH 7.0. The response to the $\mathrm{H}_{2} \mathrm{O}_{2}$ reduction was rapid, and reduction currents of $\mathrm{H}_{2} \mathrm{O}_{2}$ increased linearly with the concentrations of $\mathrm{H}_{2} \mathrm{O}_{2}$, 
as shown in Figure 5a,b. It can be seen that the reducing currents of $\mathrm{H}_{2} \mathrm{O}_{2}$ have a different sensitivity at low and high concentrations. The calibration plots with two slopes display the linear ranges of 20-100 $\mu \mathrm{M}$ and 200-1000 $\mu \mathrm{M}$ of $\mathrm{H}_{2} \mathrm{O}_{2}$ with respective correlation coefficients of 0.99 . The linear regression equations for the reduction peak currents in the two ranges are $\mathrm{I}(\mu \mathrm{A})=0.164\left[\mathrm{H}_{2} \mathrm{O}_{2}\right]+$ 0.962 and $\mathrm{I}(\mu \mathrm{A})=0.082\left[\mathrm{H}_{2} \mathrm{O}_{2}\right]+12.8$, respectively. The sensitivity obtained for $\mathrm{H}_{2} \mathrm{O}_{2}$ at the two concentration ranges were $0.164 \mu \mathrm{A} / \mu \mathrm{M}$ and $0.082 \mu \mathrm{A} / \mu \mathrm{M}$, respectively. The detection limit (DL) of $\mathrm{H}_{2} \mathrm{O}_{2}$ was calculated by the standard deviation of blank noises (number of measurements $=5,95 \%$ confidence level, signal-to-noise ratio, $\mathrm{k}=3$ ) and was determined to be $1.66 \mu \mathrm{M}$. To test the operational reproducibility of AgNPs/PEI electrodes, four AgNPs/PEI/GCEs were prepared and examined to detect $0.1 \mathrm{mM} \mathrm{H}_{2} \mathrm{O}_{2}$ by CV. These four electrodes showed a resemblance of the current response in the detection of $\mathrm{H}_{2} \mathrm{O}_{2}$ with a \% relative standard deviation of $4.18 \%$. Based on the analytical results, the analytical characteristics of the proposed electrode were compared with the previously reported AgNPs/organic polymer-coated electrode in Table 1. Unlike other electrodes, the AgNPs of this work was formed by the solid precursor of $\mathrm{AgCl}$, and the result was appreciable, as can be seen from the comparison with other works.

To evaluate the practical determination of hydrogen peroxide, the interfering effects of substances that could influence the analysis of hydrogen peroxide were investigated. Three potential interferents commonly present in human urine were selected, namely ascorbic acid (AA), uric acid (UA), and acetaminophen (AP). The AgNPs/PEI-decorated electrode was operated at $-0.4 \mathrm{~V}$, which was a sufficient reduction potential of hydrogen peroxide, and the current response was continuously measured by chronoamperometry. The obtained results (Figure 6) indicated that the proposed sensor did not respond to the three interferents and could thus be used for $\mathrm{H}_{2} \mathrm{O}_{2}$ analysis in the presence of interferents.
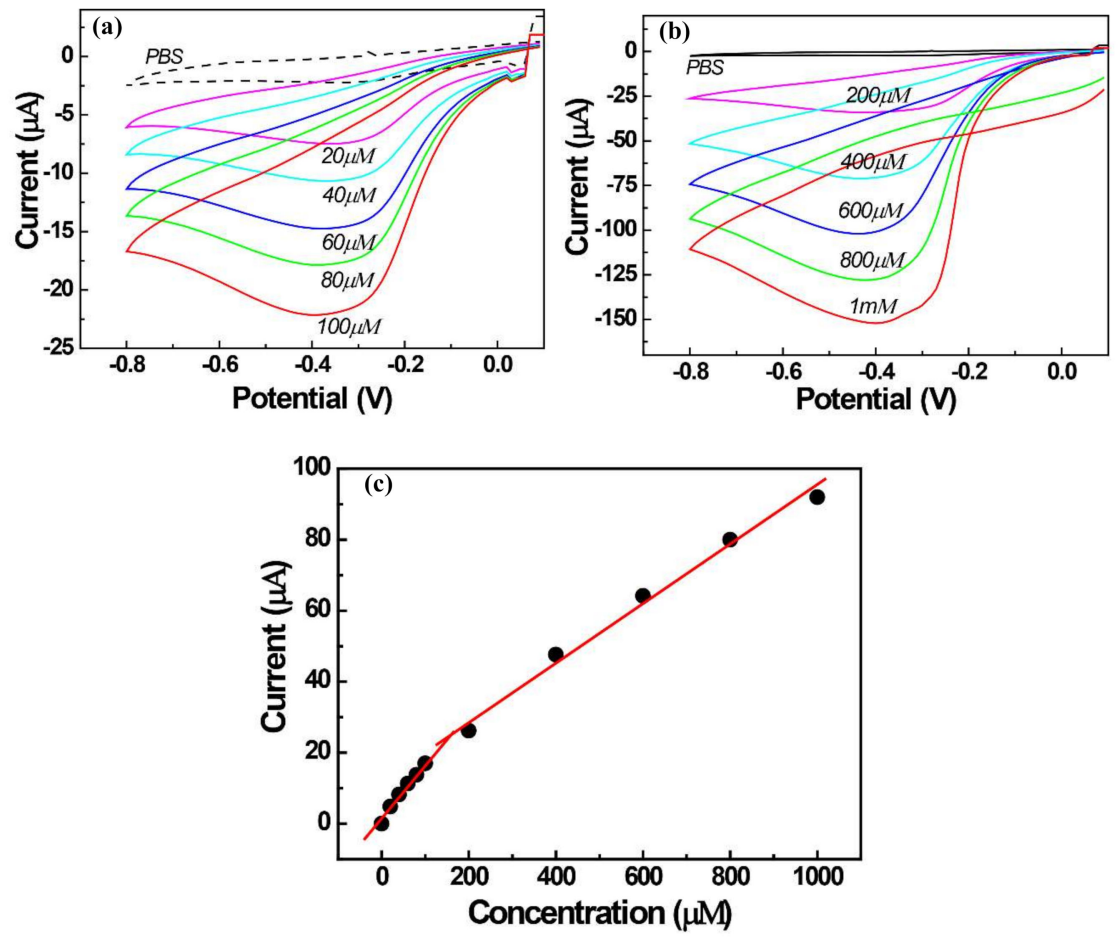

Figure 5. Cyclic voltammograms of $0.5 \mathrm{wt} / \mathrm{vol} \% \mathrm{AgNPs} / \mathrm{PEI}$-decorated GCE for $\mathrm{H}_{2} \mathrm{O}_{2}$ concentrations of (a) 20-100 $\mu \mathrm{M}$, (b) 200-1000 $\mu \mathrm{M}$, and (c) the corresponding calibration curves. 
Table 1. Performance comparison of developed AgNPs/PEI and AgNPs/organic polymer electrodes for the electrochemical determination of $\mathrm{H}_{2} \mathrm{O}_{2}$.

\begin{tabular}{|c|c|c|c|c|c|}
\hline Electrode & $\begin{array}{c}\text { Silver } \\
\text { Salt/Synthesis }\end{array}$ & Method & $\begin{array}{c}\text { Detection } \\
\text { Limit }(\mu \mathrm{M})\end{array}$ & $\begin{array}{c}\text { Dynamic } \\
\text { Range }(\mu \mathrm{M})\end{array}$ & Ref. \\
\hline AgNPs/TPDT/GCE & $\mathrm{AgNO}_{3} / \mathrm{ES}$ & LSV & 0.5 & $0.5-3.5$ & [44] \\
\hline AgNCs/PEI/GCE & $\mathrm{AgNO}_{3} / \mathrm{CS}$ & CA & 1.8 & $10-1440$ & [45] \\
\hline AgNPs/PoPD/GCE & $\mathrm{AgNO}_{3} / \mathrm{CS}$ & CA & 1.5 & $6.0-67,300$ & [46] \\
\hline AgNPs/collagen/GCE & $\mathrm{AgNO}_{3} / \mathrm{ES}$ & CA & 0.7 & $5.0-40,600$ & [47] \\
\hline AgNPs/HDMA, PEG/SPCE & $\mathrm{AgNO}_{3} / \mathrm{ES}$ & CA & 1.5 & $10-180$ & [48] \\
\hline AgNPs/PI/GCG & Commercial AgNPs & CA & 8.6 & $10-1000$ & [49] \\
\hline AgNPs/PMES/GCE & $\mathrm{AgNO}_{3} / \mathrm{ES}$ & CA & 0.18 & $0.6-540$ & [50] \\
\hline AgNPs/PEDOT/ITO & $\mathrm{AgNO}_{3} / \mathrm{ES}$ & CA & 7 & - & [51] \\
\hline AgNPs/PEI/GCE & $\mathrm{AgCl} / \mathrm{ES}$ & $\mathrm{CV}$ & 1.66 & $2-1000$ & This work \\
\hline
\end{tabular}

ES: electrochemical synthesis, CS: chemical synthesis, LSV: linear sweep voltammetry, CV: cyclic voltammetry, CA: chronoamperometry, SPCE: screen-printed carbon electrode, AgNC: silver nanocluster, TPDT: N-(3-(trimethoxysilyl) propyl) diethylenetriamine, PoPD: poly(o-phenylenediamin), HMDA: Hexamethylenediamine, PEG: poly(ethylene glycol), PI: polyimide, PMES: poly(2-(N-morpholine) ethane sulfonic acid), PEDOT: poly(3,4-ethylenedioxythiophene), ITO: indium tin oxide.

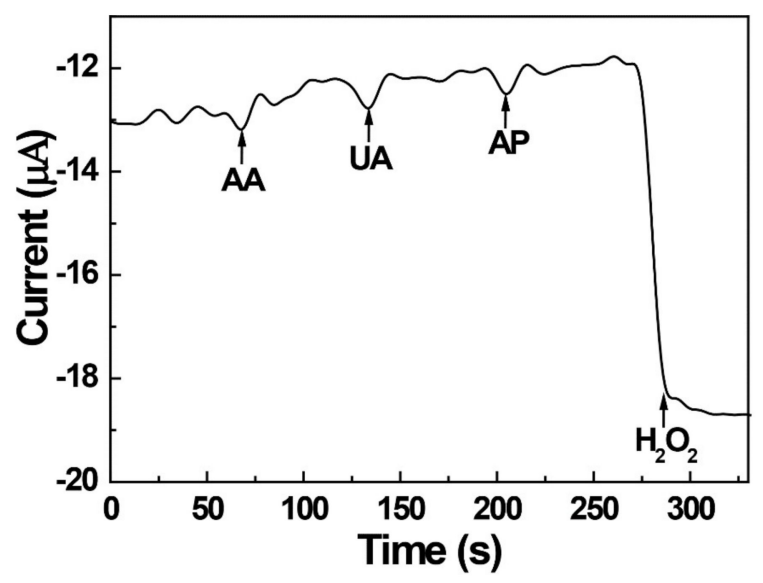

Figure 6. Amperometric responses of the AgNPs/PEI-decorated GCE to injections of $0.5 \mathrm{mM}$ ascorbic acid (AA), uric acid (UA), acetaminophen (AP), and $\mathrm{H}_{2} \mathrm{O}_{2}$.

$\mathrm{H}_{2} \mathrm{O}_{2}$ in the human body has been known as a biomarker of oxidative stress, and in urine it may control catabolism and renal function, as well as acting as an antibacterial agent [52-54]. A common level in healthy human urine was found in the micromolar range (1-100 $\mu \mathrm{M})$, but concentrations lower than $1 \mu \mathrm{M}$ were observed according to individuals' health conditions [53]. The concentration of inherent hydrogen peroxide in the present urine sample was analyzed using the AgNPs/PEI-decorated electrode, but the current of hydrogen peroxide was not observed. These results are assumed to be due to the presence of hydrogen peroxide below the detection limit in the present urine sample. The reliability of the AgNPs/PEI-decorated electrode was evaluated by determining the $\mathrm{H}_{2} \mathrm{O}_{2}$ concentration in a real sample of human urine, where the urine samples were diluted five times with 0.1 M PBS. Chronoamperometry measurements were performed to determine the concentration of $\mathrm{H}_{2} \mathrm{O}_{2}$, and calibration plots were constructed using the standard addition method. $\mathrm{A}_{2} \mathrm{O}_{2}$ standard solution was added to the diluted urine sample, and the concentration of hydrogen peroxide to be analyzed was measured using the AgNPs/PEI-decorated electrode. Table 2 shows the analytical values obtained for three urine samples tested. The average recovery of spiked 2.5- $\mu \mathrm{M} \mathrm{H}_{2} \mathrm{O}_{2}$ urine samples was $98.4 \%$ for three repeat measurements with $4.67 \%$ for the $\%$ relative standard deviation (\% RSD), which indicated the appreciable practicality of catalytic $\mathrm{H}_{2} \mathrm{O}_{2}$ determination in real samples. 
Table 2. Determination of $\mathrm{H}_{2} \mathrm{O}_{2}$ in human urine samples at the AgNPs/PEI-decorated electrode $(n=3)$.

\begin{tabular}{cccc}
\hline Sample & Spiked $(\boldsymbol{\mu M})$ & Found $(\boldsymbol{\mu M})$ & Recovery $(\%)$ \\
\hline 1 & 2.5 & 2.42 & 96.8 \\
2 & 2.5 & 2.37 & 94.8 \\
3 & 2.5 & 2.59 & 103.6 \\
Average & 2.5 & $\mathbf{2 . 4 6}$ & $\mathbf{9 8 . 4}$ \\
\hline
\end{tabular}

\section{Materials and Methods}

\subsection{Materials}

$\mathrm{AgCl}$, polyelthyleneimine (PEI, $\mathrm{M}$ W $1300 \mathrm{~g} / \mathrm{mol}$ ), $\mathrm{NaH}_{2} \mathrm{PO}_{4}, \mathrm{Na}_{2} \mathrm{HPO}_{4}, \mathrm{H}_{2} \mathrm{O}_{2}, \mathrm{~N}$-acetyl-paraaminophenol (acetaminophen), ascorbic acid (AA), and uric acid (UA) were purchased from Aldrich (USA). All $\mathrm{H}_{2} \mathrm{O}_{2}$ and 0.1 M PBS ( $\mathrm{pH} 7.0$ ) solutions were prepared fresh each day.

\subsection{Characterization}

Cyclic voltammetry $(\mathrm{CV})$ and controlled-potential electrolysis were performed for a conventional three-electrode cell $(\mathrm{Ag} / \mathrm{AgCl}$ (saturated $\mathrm{KCl}), \mathrm{Pt}$ wire, and a glassy carbon electrode (GCE, diameter $=3 \mathrm{~mm}$ ) as the reference, counter, and working electrodes, respectively) using an IVIUM electrochemical workstation (Eindhoven, Netherland). Prior to each experiment, the GCE was polished using 0.3- and 0.05- $\mu \mathrm{m}$ alumina powders, followed by washing with ethanol and distilled water, and nitrogen gas was purged through the solution for $5 \mathrm{~min}$ to remove dissolved oxygen. Field emission scanning electron microscopy (FE-SEM) images and EDS data were acquired using FE-SEM SUPRA25 (Carl Zeiss, Oberkochen, Germany). An X-ray photoelectron spectroscopy (XPS) analysis was performed at KBSI (Busan, Korea) on a Theta Probe AR-XPS spectrometer (Thermo Fisher Scientific, East Grinstead, UK) using monochromated $\mathrm{Al} K_{\alpha}$ radiation $(1486.6 \mathrm{eV})$ at an $\mathrm{X}$-ray power of $100 \mathrm{~W}$ and an energy step of $0.1 \mathrm{eV}$. The $\mathrm{C} 1 \mathrm{~s}$ line, with a binding energy of $284.6 \mathrm{eV}$, was utilized as an internal reference for calibration. For the SEM, XPS, and EDS experiments, a cylindrical glassy carbon rod (diameter $=3 \mathrm{~mm}$ ) was cut to a thickness of $2 \mathrm{~mm}$, after which a thin GCE was prepared by directly connecting a peace of rod and $\mathrm{Cu}$ wire using conductive ink.

\subsection{Preparation of PEI-Encapsulated AgNPS}

Figure 7 shows the schematic of the AgNPs/PEI fabrication process from solid AgCl-supported PEI. Before mixing the solid $\mathrm{AgCl}$ and $\mathrm{PEI}$ solution, $\mathrm{AgCl}$ was ground into fine powder with a mortar. Solid AgCl-supported PEI coatings (AgCl/PEI = 0.05, 0.5, $5.0 \mathrm{wt} / \mathrm{vol} \%$ ) were prepared by directly mixing powdered $\mathrm{AgCl}$ with $1.0 \mathrm{wt} \%$ aqueous PEI. To prepare a $0.5 \mathrm{wt} / \mathrm{vol} \% \mathrm{AgCl} / \mathrm{PEI}$ mixture, $0.5 \mathrm{mg}$ of finely ground solid $\mathrm{AgCl}$ was mixed with $100 \mu \mathrm{L}$ of $1.0 \mathrm{wt} \%$ PEI solution over $30 \mathrm{~s}$ of sonication, and the GCE surface was drop-coated with a $5-\mu \mathrm{L}$ aliquot of the above mixture and dried at room temperature for $10 \mathrm{~min}$. After drying, $\mathrm{AgCl}$ was electrochemically reduced in $\mathrm{PBS}(\mathrm{pH} 7.0)$ at a constant potential of $-0.5 \mathrm{~V}$ applied for $300 \mathrm{~s}$ or potential cycling.

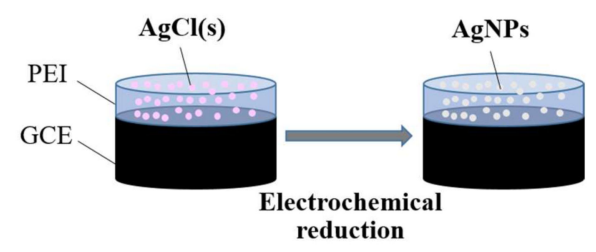

Figure 7. Schematic representation of the fabrication process of AgNPs/PEI-decorated. 


\section{Conclusions}

We developed a simple method for electrochemically fabricating silver nanoparticles (AgNPs) using solid silver salt of silver chloride. The finely ground solid silver chloride ( $\mathrm{AgCl}$ ) was mixed with a poltethyleneimine (PEI) and coated to the electrode surface of a glassy carbon electrode. A reduction potential or potential cycling techniques were applied, and AgNPs were successfully formed on the electrode surface. The characterization of the synthesized AgNPs was performed via scanning electron microscopy (SEM), X-ray photoelectron spectroscopy (XPS), and energy dispersive X-ray spectroscopy (EDS). The AgNPs/PEI showed an excellent electrocatalytic activity to $\mathrm{H}_{2} \mathrm{O}_{2}$ reduction through a potential shift and by significantly increasing the reduction peak current. Based on the result of the catalytic effect on the $\mathrm{H}_{2} \mathrm{O}_{2}$ reduction, the AgNPs/PEI electrode was applied to the electrochemical analysis of the $\mathrm{H}_{2} \mathrm{O}_{2}$ reduction. As the concentration of $\mathrm{H}_{2} \mathrm{O}_{2}$ increased, the catalytic reduction current of $\mathrm{H}_{2} \mathrm{O}_{2}$ increased linearly, and the interfering effect of the interfering substances was also eliminated. The sensitive and specific response to the $\mathrm{H}_{2} \mathrm{O}_{2}$ reduction demonstrates that the AgNPs/PEI electrode is suitable for the determination of $\mathrm{H}_{2} \mathrm{O}_{2}$ concentrations in a biological system. To confirm the actual performance of the AgNPs/PEI, it was applied to a human urine sample and showed reliable results using a spike recovery test.

Author Contributions: Conceptualization, D.-S.P.; methodology, K.T.K. and D.-S.P.; validation, K.T.K. and D.-S.P.; formal analysis, K.T.K.; investigation, K.T.K. and D.-S.P.; resources, D.-S.P.; data curation, K.T.K. and D.-S.P.; writing — original draft preparation, K.T.K.; writing—review and editing, D.-S.P.; visualization, K.T.K.; supervision, D.-S.P.; project administration, D.-S.P.; funding acquisition, D.-S.P. All authors have read and agreed to the published version of the manuscript.

Funding: This research received no external funding.

Acknowledgments: This work was supported by a 2-Year Research Grant of Pusan National University.

Conflicts of Interest: The authors declare no conflict of interest.

\section{References}

1. Syafiuddin, A.; Salim, M.R.; Beng Hong Kueh, A.; Hadibarata, T.; Nur, H. A review of silver nanoparticles: Research trends, global consumption, synthesis, properties, and future challenges. J. Chin. Chem. Soc. 2017, 64, 732-756. [CrossRef]

2. Lee, S.H.; Jun, B.H. Silver nanoparticles: Synthesis and application for nanomedicine. Int. J. Mol. Sci. 2019, 20, 865. [CrossRef] [PubMed]

3. Levard, C.; Hotze, E.M.; Lowry, G.V.; Brown, G.E., Jr. Environmental transformations of silver nanoparticles: Impact on stability and toxicity. Environ. Sci. Technol. 2012, 46, 6900-6914. [CrossRef] [PubMed]

4. Tsuji, T.; Iryo, K.; Watanabe, N.; Tsuji, M. Preparation of silver nanoparticles by laser ablation in solution: Influence of laser wavelength on particle size. Appl. Surf. Sci. 2002, 202, 80-85. [CrossRef]

5. Asanithi, P.; Chaiyakun, S.; Limsuwan, P. Growth of silver nanoparticles by DC magnetron sputtering. J. Nanomater. 2012, 2012, 963609. [CrossRef]

6. Hussain, J.I.; Kumar, S.; Hashmi, A.A.; Khan, Z. Silver nanoparticles: Preparation, characterization, and kinetics. Adv. Mater. Lett. 2011, 2, 188-194. [CrossRef]

7. Khan, Z.; Al-Thabaiti, S.A.; Obaid, A.Y.; Al-Youbi, A.O. Preparation and characterization of silver nanoparticles by chemical reduction method. Colloid. Surf. B Biointerfaces 2011, 82, 513-517. [CrossRef]

8. Yin, B.; Ma, H.; Wang, S.; Chen, S. Electrochemical synthesis of silver nanoparticles under protection of poly(N-vinylpyrrolidone). J. Phys. Chem. B 2003, 107, 8898-8904. [CrossRef]

9. Kuntyi, O.L.; Kytsya, A.R.; Mertsalo, I.P.; Mazur, A.S.; Zozula, G.I.; Bazylyak, L.I.; Topchak, R.V. Electrochemical synthesis of silver nanoparticles by reversible current in solutions of sodium polyacrylate. Colloid Polym. Sci. 2019, 297, 689-695. [CrossRef]

10. Soliveri, G.; Ardizzone, S.; Yüksel, S.; Cialla-May, D.; Popp, J.; Schubert, U.S.; Hoeppener, H. Microwave-assisted silver nanoparticle film formation for SERS applications. J. Phys. Chem. C 2016, 120, 1237-1244. [CrossRef] 
11. Itoh, M.; Kakuta, T.; Nagaoka, M.; Koyama, Y.; Sakamoto, M.; Kawasaki, S.; Umeda, N.; Kurihara, M. Direct transformation into silver nanoparticles via thermal decomposition of oxalate-bridging silver oleylamine complexes. J. Nanosci. Nanotechnol. 2009, 9, 6655-6660. [CrossRef] [PubMed]

12. Siddiqi, K.S.; Husen, A.; Rao, R. A review on biosynthesis of silver nanoparticles and their biocidal properties. J. Nanobiotechnol. 2018, 16, 1-28. [CrossRef] [PubMed]

13. Mohd Abdah, M.A.A.; Razali, N.S.M.; Lim, P.T.; Kulandaivalu, S.; Sulaiman, Y. One-step potentiostatic electrodeposition of polypyrrole/graphene oxide/multi-walled carbon nanotubes ternary nanocomposite for supercapacitor. Mater. Chem. Phys. 2018, 219, 120-128. [CrossRef]

14. Ma, H.; Yin, B.; Wang, S.; Jioo, Y.; Pan, W.; Huang, S.; Chen, S.; Meng, F. Synthesis of silver and gold nanoparticles by a novel electrochemical method. Chem. Phys. Chem. 2004, 5, 68-75. [CrossRef]

15. Rodriguez-Sanchez, L.; Blanco, M.C.; Lopez-Quintela, M.A. Electrochemical synthesis of silver nanoparticles. J. Phys. Chem. B 2000, 104, 9683-9688. [CrossRef]

16. Starowicz, M.; Stypuła, B.; Banaś, J. Electrochemical synthesis of silver nanoparticles. Electrochem. Commun. 2006, 8, 227-230. [CrossRef]

17. Nešović, K.; Mišković-Stanković, V. A comprehensive review of the polymer-based hydrogels with electrochemically synthesized silver nanoparticles for wound dressing applications. Polym. Eng. Sci. 2020, 60, 1393-1419. [CrossRef]

18. Gupta, R.; Jayachandran, K.; Gamare, J.S.; Rajeshwari, B.; Gupta, S.K.; Kamat, J.V. Fabrication of silver nanoparticles-polypyrrole composite modified electrode for electrocatalytic oxidation of hydrazine. Synth. Met. 2014, 195, 234-240.

19. Xie, C.; Lu, X.; Wang, K. Pulse electrochemical synthesis of spherical hydroxyapatite and silver nanoparticles mediated by the polymerization of polypyrrole on metallic implants for biomedical applications. Part. Part. Syst. Charact. 2015, 32, 630-635. [CrossRef]

20. Hosseini, M.; Momeni, M.M. Silver nanoparticles dispersed in polyaniline matrixes coated on titanium substrate as a novel electrode for electro-oxidation of hydrazine. J. Mater. Sci. 2010, 45, 3304-3310. [CrossRef]

21. Cai, Z.; Xiong, H.; Zhu, Z.; Huang, H.; Li, L.; Huang, Y. Electrochemical synthesis of graphene/polypyrrole nanotube composites for multifunctional applications. Synth. Met. 2017, 227, 100-105. [CrossRef]

22. Liu, X.; Wei, H.; Song, G.; Guo, H.; Lu, X. Sensitive detection of superoxide anion released from living cells using silver nanoparticles and functionalized multiwalled carbon nanotube composite. Sens. Actuators B Chem. 2017, 252, 503-510. [CrossRef]

23. Wen, S.; Zheng, F.; Shen, M.; Shi, X. Synthesis of polyethyleneimine-stabilized gold nanoparticles for colorimetric sensing of heparin. Colloids Surf. A Physicochem. Eng. Aspects 2013, 419, 80-86. [CrossRef]

24. Yuan, Z.; Cai, N.; Du, Y.; He, Y.; Yeung, E.S. Sensitive and selective detection of copper ions with highly stable polyethyleneimine-protected silver nanoclusters. Anal. Chem. 2014, 86, 419-426. [CrossRef]

25. Gao, X.; Li, Y.; Zhang, Q.; Li, S.; Chen, Y.; Lee, J.M. Polyethyleneimine-assisted synthesis of high-quality platinum/graphene hybrids: The effect of molecular weight on electrochemical properties. J. Mater. Chem. A 2015, 3, 12000-12004. [CrossRef]

26. Welch, C.M.; Banks, C.E.; Simm, A.O.; Compton, R.G. Silver nanoparticle assemblies supported on glassy-carbon electrodes for the electro-analytical detection of hydrogen peroxide. Anal. Bioanal. Chem. 2005, 382, 12-21. [CrossRef]

27. Xu, S.X.; Huang, X.; Chen, Y.; Liu, Y.; Zhao, W.; Sun, Z.; Zhu, Y.; Liu, X.; Wong, C.P. Silver nanoparticle-enzyme composite films for hydrogen peroxide detection. ACS Appl. Nano Mater. 2019, 2, 5910-5921. [CrossRef]

28. Khan, A.Y.; Bandyopadhyaya, R. Silver nanoparticle impregnated mesoporous silica as a non-enzymatic amperometric sensor for an aqueous solution of hydrogen peroxide. J. Electroanal. Chem. 2014, 727, 184-190. [CrossRef]

29. Yin, J.; Qi, X.; Yang, L.; Hao, G.; Li, J.; Zhong, J. A hydrogen peroxide electrochemical sensor based on silver nanoparticles decorated silicon nanowire arrays. Electrochimica Acta 2011, 56, 3884-3889. [CrossRef]

30. Ghosale, A.; Shrivas, K.; Shankar, R.; Ganesan, V. Low-cost paper electrode fabricated by direct writing with silver nanoparticle-based ink for detection of hydrogen peroxide in wastewater. Anal. Chem. 2017, 89, 776-782. [CrossRef]

31. Wang, N.; Miller, C.J.; Wang, P.; Waite, T.D. Quantitative determination of trace hydrogen peroxide in the presence of sulfide using the Amplex Red/horseradish peroxidase assay. Anal. Chim. Acta 2017, 963, 61-67. [CrossRef] [PubMed] 
32. Yuen, J.W.M.; Benzie, I.F.F. Hydrogen peroxide in urine as a potential biomarker of whole body oxidative stress. Free Radic. Res. 2003, 37, 1209-1213. [CrossRef] [PubMed]

33. Kwon, S.R.; Wertz, P.W.; Dawson, D.V.; Cobb, D.S.; Denehy, G. The relationship of hydrogen peroxide exposure protocol to bleaching efficacy. Oper. Dent. 2013, 38, 177-185. [CrossRef] [PubMed]

34. Smirnoff, N.; Arnaud, D. Hydrogen peroxide metabolism and functions in plant. New Phytol. 2019, 221, 1197-1214. [CrossRef] [PubMed]

35. He, P.; Liu, H.; Li, Z.; Liu, Y.; Xu, X.; Li, J. Electrochemical deposition of silver in room-temperature ionic liquids and its surface-enhanced Raman scattering effect. Langmuir 2004, 20, 10260-10267. [CrossRef]

36. Cloake, S.J.; Toh, H.S.; Lee, P.T.; Salter, C.; Johnston, C.; Compton, R.G. Anodic stripping voltammetry of silver nanoparticles: Aggregation leads to incomplete stripping. ChemistryOpen 2015, 4, 22-26. [CrossRef]

37. Zheng, B.; Wong, L.P.; Wu, L.Y.L.; Chen, Z. Cyclic voltammetric study of high speed silver electrodeposition and dissolution in low cyanide solutions. Int. J. Electrochem. 2016, 2016, 1-11. [CrossRef]

38. Prieto, P.; Nistor, V.; Nouneh, K.; Oyama, M.; Abd-Lefdil, M.; Díaz, R. XPS study of silver, nickel and bimetallic silver-Nickel nanoparticles prepared by seed-mediated growth. App. Surf. Sci. 2012, 258,8807-8813. [CrossRef]

39. Fan, Y.; Bao, Y.; Song, Z.; Sun, Z.; Wang, D.; Han, D.; Niua, L. Controllable synthesis of coloured $\mathrm{Ag}^{0} / \mathrm{AgCl}$ with spectral analysis for photocatalysis. RSC Adv. 2018, 8, 24812-24818. [CrossRef]

40. Crist, B.V. Handbooks of Monochromatic XPS Spectra; XPS International LLC: Mountain View, CA, USA, 1999; pp. 1-4, 313-317.

41. Lopez-Salido, I.; Lim, D.C.; Kim, Y.D. Ag nanoparticles on highly ordered pyrolytic graphite (HOPG) surfaces studied using STM and XPS. Surf. Sci. 2005, 588, 6-18. [CrossRef]

42. Marinho, H.S.; Real, C.; Cyrne, L.; Soares, H.; Antunes, F. Hydrogen peroxide sensing, signaling and regulation of transcription factors. Redox Biol. 2014, 2, 535-562. [CrossRef]

43. Lee, M.; Heikes, B.G.; O'Sullivan, D.W. Hydrogen peroxide and organic hydroperoxide in the troposphere: A review. Atmos. Environ. 2000, 34, 3475-3494. [CrossRef]

44. Rameshkumar, P.; Viswanathan, P.; Ramasamy, R. Silicate sol-gel stabilized silver nanoparticles for sensor applications toward mercuric ions, hydrogen peroxide and nitrobenzene. Sens. Actuators B Chem. 2014, 202, 1070-1077. [CrossRef]

45. Li, B.L.; Chen, J.R.; Luo, H.Q.; Li, N.B. Electrocatalytic activity of polymer-stabilized silver nanoclusters for hydrogen peroxide reduction. J. Electroanal. Chem. 2013, 706, 64-68. [CrossRef]

46. Wang, L.; Zhu, H.; Song, Y.; Liu, L.; He, Z.; Wan, L.; Chen, S.; Xiang, Y.; Chen, S.; Chen, J. Architecture of poly(o-phenylenediamine)-Ag nanoparticle composites for a hydrogen peroxide sensor. Electrochim. Acta 2012, 60, 314-320. [CrossRef]

47. Song, Y.; Cui, K.; Wang, L.; Chen, S. The electrodeposition of Ag nanoparticles on a type I collagen-modified glassy carbon electrode and their applications as a hydrogen peroxide sensor. Nanotechnology 2009, 20, 105501. [CrossRef]

48. Goug, K.Y.; Kumar, V.S.; Hayat, A. Polymer scaffold layers of screen-printed electrodes for homogeneous deposition of silver nanoparticles: Application to the amperometric detection of hydrogen peroxide. Microchim. Acta 2019, 186, 810.

49. Chen, L.; Wang, Y.; Ban, H.; Yu, S.; Hu, Z. An amperometric sensitive hydrogen peroxide sensor based on a silver nanoparticle-doped polyimide-modified glassy carbon electrode. Int. J. Electrochem. Sci. 2018, 13, 10961-10972.

50. Zhang, K.; Zhang, N.; Xu, J.; Wang, H.; Wang, C.; Shi, H.; Liu, C. Silver nanoparticles/poly(2-(N-morpholine) ethane sulfonic acid) modified electrode for electrocatalytic sensing of hydrogen peroxide. J. Appl. Electrochem. 2011, 41, 1419-1423. [CrossRef]

51. Balamurugan, A.; Chen, S.M. Silver nanograins incorporated PEDOT modified electrode for electrocatalytic sensing of hydrogen peroxide. Electroanalysis 2009, 21, 1419-1423. [CrossRef]

52. Barry Halliwell, B.; Lee, H.L.; Tsin, P.Y.; Lim, S.; Kelly, R. Establishing biomarkers of oxidative stress: The measurement of hydrogen peroxide in human urine. Curr. Med. Chem. 2004, 11, 1085-1092. [CrossRef] [PubMed]

53. Long, L.H.; Evans, P.J.; Halliwell, B. Hydrogen peroxide in human urine: Implications for antioxidant defense and redox regulation. Biochem. Biophys. Res. Commun. 1999, 262, 605-609. [CrossRef] [PubMed] 
54. Halliwella, B.; Clement, M.V.; Long, L.H. Hydrogen peroxide in the human body. FEBS Lett. 2000, 486, 10-13. [CrossRef]

Publisher's Note: MDPI stays neutral with regard to jurisdictional claims in published maps and institutional affiliations.

(C) 2020 by the authors. Licensee MDPI, Basel, Switzerland. This article is an open access article distributed under the terms and conditions of the Creative Commons Attribution (CC BY) license (http://creativecommons.org/licenses/by/4.0/). 